\title{
PENGARUH KUALITAS PRODUK TERHADAP KEPUASAN KONSUMEN DI RESTORAN BEBEK DAN AYAM GORENG PAK NDUT SOLO
}

\author{
Yetty Husnul Hayati \\ Dosen Tetap Fakultas Ekonomi Universitas Pakuan \\ Lecturer of Economic Faculty at Pakuan University \\ Gracia Sekartaji \\ Mahasiswa Fakultas Ekonomi Universitas Pakuan \\ Student of Economic Faculty at Pakuan University
}

\begin{abstract}
ABSTRAK
Penelitian ini mengenai Pengaruh Kualitas Produk, Pengaruh Kepuasan konsumen serta Pengaruh kualitas produk terhadap Kepuasan Konsumen yang dilakukan pada Rumah Makan Bebek dan Ayam Goreng Pak Ndut. Metode analisis yang digunakan adalah kuantitatif statistik. Adapun analisis data yang dipakai yaitu Analisis Koefisien Korelasi. Hasil Penelitian mengungkapkan fakta bahwa Kualitas produk berpengaruh terhadap kepuasan konsumen, hal tersebut dapat dilihat pada tabel Correlation yang didapat sebesar $\mathrm{r}_{\mathrm{xy}}$ 0.710, dan nilai $\mathrm{r}_{\text {tabel }}$ pada $d f 398$ adalah 0.098. maka dapat diartikan terdapat hubungan yang positif antara produk terhadap kepuasan pelanggan pada rumah makan bebek dan ayam goreng pak ndut solo. Berdasarkan indeks tingkat kepuasan konsumen dapat dilihat bahwa rata-rata Tki adalah $100.1 \%$ yang dapat diartikan bahwa konsumen merasa puas dengan kualitas produk yang ada di rumah makan bebek dan ayam goreng pak ndut solo. Bila dilihat berdasarkan uji $f$ dan $t$, uji f menyatakan bahwa nilai $F$ hitung > F tabel yaitu 89,621 > 1,96 dan berdasarkan uji t menyatakan bahwa t hitung memiliki nilai yang lebih besar dari nilai t tabel yaitu 1,966>0,05, yang berarti terdapat hubungan yang signifikan antara variabel independen yaitu Kualitas Produk dari rumah makan Bebek dan Ayam Goreng Pak Ndut dengan Kepuasan Konsumen.
\end{abstract}

Kata kunci: Kualitas produk dan kepuasan konsumen

\begin{abstract}
This study is about the Effect of Product Quality, Customer Satisfaction and Influence Effect of product quality to customer satisfaction conducted on Eating Duck and Chicken Fry Pak Ndut's Restaurant. The analytical method used is quantitative statistics. The analysis of the data used is Analysis Correlation Coefficient. Research results revealed the fact that the product quality affects customer satisfaction, it can be seen in the table Correlation obtained for rxy 0710, and the value r tabel on 398 df is 0.098. it means there is a positive relationship between the products to customer satisfaction at home eating duck and chicken fried Pak Ndut Solo. Based on the index level of customer satisfaction can be seen that the average Tki is $100.1 \%$, which means that consumers are satisfied with the quality of existing products at home eating duck and chicken fried Pak Ndut Solo. When viewed by test $f$ and $t, f$ test states that the value of $F$ count $>F$ table that is 89.621> 1.96 by $t$-test and stated that $t$ has a value greater than the value $t$ table is 1.966>0.05, which means There is a significant relationship between the independent variables, Quality Products from duck and chicken fried Pak Ndut'S restaurant with Consumer Satisfaction.
\end{abstract}

Keywords: Product quality and consumer satisfaction

\section{Pendahuluan}

Saat ini banyak usaha yang sudah berkembang dengan pesat, hal ini disebabkan dengan adanya ide kreatif dan inovatif. Seiring dengan ide tersebut konsep pemasaran pun turut berkembang. Kegiatan pemasaran sekarang sudah mulai difokuskan pada kepuasan konsumen. Pada umumnya setiap usaha bertujuan untuk mencari keuntungan, tujuan tersebut tidak terlepas dari kegiatan pemasaran. Pemasaran itu sendiri sudah harus dipikirkan sebelumnya, agar lebih tepat pada sasaran konsumen. Karena konsumen yang potensial akan 
mempertimbangkan berbagai faktor, diantaranya faktor kualitas produk sehingga membuat konsumen merasa sangat puas dan lebih memilih produk kita daripada produk pesaing yang lain.

Produk memiliki arti penting bagi perusahaan karena tanpa adanya produk, perusahaan tidak akan dapat melakukan apapun dari usahanya. Konsumen akan membeli produk kalau mereka tertarik dan merasa cocok, karena itu produk harus disesuaikan dengan keinginan ataupun kebutuhan pembeli agar pemasaran produk berhasil. Dengan kata lain, pembuatan produk lebih baik diorientasikan pada keinginan pasar atau selera konsumen. Menurut Kotler (2005:49), "Kualitas produk adalah keseluruhan ciri serta dari suatu produk atau pelayanan pada kemampuan untuk memuaskan kebutuhan yang dinyatakan/ tersirat".

Dengan adanya kualitas produk yang baik inilah yang akan membuat para konsumen puas dan percaya. Kepuasan pelanggan merupakan hal yang perlu diperhatikan oleh produsen. Kepuasan pelanggan merupakan suatu tingkatan dimana kebutuhan, keinginan dan harapan dari pelanggan dapat terpenuhi yang akan mengakibatkan terjadinya pembelian ulang atau kesetiaan yang berlanjut (Band, 1991). Faktor yang paling penting untuk menciptakan kepuasan konsumen adalah kinerja dari agen yang biasanya diartikan dengan kualitas dari agen tersebut (Mowen,1995).
Bila apa yang diinginkan oleh konsumen terpenuhi otomatis konsumen akan semakin puas. Produsen harus mempunyai strategi untuk meningkatkan kualitas produk, agar konsumen tetap membeli produk secara terus menerus. Pembeliaan terus menerus mengartikan bahwa konsumen memiliki loyalitas terhadap produk. Oleh karna itu produsen harus menjual kualitas produk mereka sesuai dengan harga layak. Adapun tujuan dari penelitian ini adalah 1) Untuk mengetahui kualitas produk yang ada di Rumah makan Bebek dan Ayam Goreng Pak Ndut Solo; 2) Untuk mengetahui bagaimana kepuasan konsumen terhadap Rumah makan Bebek dan Ayam Goreng Pak Ndut; dan 3) Untuk menjelaskan bagaimana pengaruh Kualitas produk terhadap kepuasan konsumen di Rumah makan Bebek dan Ayam Goreng Pak Ndut Solo

\section{Metode Penelitian}

Jenis penelitian yang dipakai adalah penelitiaan kuantitatif tentang kualitas produk mengenai kepuasan konsumen di rumah makan bebek dan ayam goreng Pak Ndut di mana penelitian akan dibuktikan dengan metode analisis statistik.

\section{Pembahasan}

3.1. Pengaruh Kualitas Produk
terhadap Kepuasan Konsumen
pada Rumah Makan Bebek dan
Ayam Goreng Pak Ndut

$$
\begin{aligned}
& r x y=\frac{N \cdot \sum X Y-\sum X \cdot \sum Y}{\sqrt{\left\{N \cdot \sum X^{2}-\left(\sum X^{2}\right)\right\} \cdot\left\{N \cdot \sum Y^{2}-\left(\sum Y\right)^{2}\right\}}} \\
& r x y=\frac{400.112500-13330.3350}{\sqrt{\left\{400.447610-(13330)^{2}\right\} .\left\{400.28490-(3350)^{2}\right\}}} \\
& r x y=\frac{45000000-44655500}{\sqrt{\{(179044000-177688900) \cdot(11396000-11222500)\}}}
\end{aligned}
$$


*Tabel Koefisien terlampir

$$
\begin{gathered}
r x y=\frac{344500}{\sqrt{1355100.173500}} \\
r x y=\frac{344500}{\sqrt{235109850000}} \\
r x y=\frac{344500}{48481,2741} \\
r x y=0.710
\end{gathered}
$$

Dari hasil hitungan di atas maka dapat dilihat hasil koefisien sebesar 0.710. Untuk menentukan signifikansi antara produk dan pelayanan maka peneliti menggunakan koefisien produk moment dan membandingkannya dengan hasil $\mathrm{r}$ tabel. Dengan taraf signifikan 5\% untuk $N=400$ orang. Selanjutnya menghitung $d f$ (derajat bebas dengan tingkat kepercayaan $0.5 \%$ ):

$$
\begin{gathered}
D F=N-2 \\
D F=400-2
\end{gathered}
$$

$$
D F=398
$$

Dari perhitungan nilai product moment didapat nilai $r_{x y} 0.710$, dan nilai $\mathrm{r}_{\text {tabel }}$ pada $d f 398$ adalah 0.098 , maka dapat disimpulkan bahwa semakin meningkat kualitas produk dan pelayanan maka semakin tinggi pula tingkat kepuasan pelanggan pada rumah makan bebek dan ayam goreng pak ndut atau terdapat hubungan yang positif antara produk dan pelayanan terhadap kepuasan pelanggan pada rumah makan bebek dan ayam goreng pak ndut solo.

Tabel 3.1.

Nilai Koefisien dan Tingkat Pengaruh

Value Coefficient and Effect Levels

\begin{tabular}{|l|l|}
\hline Interval Koefisien & Tingkat pengaruh \\
\hline$<0,20$ & Rendah \\
\hline $0,20<-=0,40$ & Sedang \\
\hline $0,40<-=0,60$ & Cukup Kuat \\
\hline $0,60<-=0,80$ & Kuat \\
\hline $0,80<-=1,00$ & Sangat Kuat \\
\hline
\end{tabular}

Prosedur korelasi bivariat menghitung pasangan pengaruh untuk suatu set variabel dan menampilkan hasilnya pada suatu matrix. Hal ini digunakan untuk menentukan kekuatan dan arah hubungan antara dua variabel, nilai koefisien korelasi antara -1 sampai dengan 1. Maka nilai koefisien 0 (nol) menunjukkan tidak adanya pengaruh antara dua variabel.

Dari hasil perhitungan product moment diatas maka dapat diartikan nilai tersebut memiliki hubungan yang Kuat dan juga ini berarti ada korelasi yang positif antara produk dengan kepuasan pelanggan. Nilai tersebut juga mengartikan menolak hipotesis nol (Ho) dan menerima hipotesis alternatif (Ha), yang berarti terdapat hubungan yang signifikan antara variabel independen yaitu Kualitas Produk dari rumah makan Bebek dan Ayam Goreng Pak Ndut terhadap Kepuasan Konsumen. 
Tabel 3.2.

Analisis Regresi Berganda

Multiple Regression Analysis

Coefficients $^{\mathrm{a}}$

\begin{tabular}{|c|c|c|c|c|c|c|}
\hline \multirow{2}{*}{\multicolumn{2}{|c|}{ Model }} & \multicolumn{2}{|c|}{$\begin{array}{l}\text { Unstandardized } \\
\text { Coefficients }\end{array}$} & $\begin{array}{l}\text { Standardized } \\
\text { Coefficients } \\
\end{array}$ & \multirow[t]{2}{*}{$\mathrm{T}$} & \multirow[t]{2}{*}{ Sig. } \\
\hline & & B & Std. Error & Beta & & \\
\hline \multirow{9}{*}{1} & (Constant) & .086 & .400 & & .216 & .829 \\
\hline & $\mathrm{X} 1$ & .058 & .126 & .025 & .461 & .645 \\
\hline & $\mathrm{X} 2$ & .020 & .091 & .011 & .219 & .827 \\
\hline & $\mathrm{X} 3$ & .617 & .093 & .310 & 6.645 & .000 \\
\hline & $\mathrm{X} 4$ & -.340 & .104 & -.142 & -3.276 & .001 \\
\hline & $\mathrm{X} 5$ & .739 & .095 & .368 & 7.757 & .000 \\
\hline & X6 & -.204 & .105 & -.109 & -1.944 & .053 \\
\hline & $\mathrm{X} 7$ & 1.086 & .113 & .489 & 9.615 & .000 \\
\hline & $\mathrm{X} 8$ & .050 & .095 & .023 & .523 & .602 \\
\hline
\end{tabular}

a. Dependent Variable: Y

Dari tabel diatas maka didapatkan hasil perhitungan sebagai berikut:

$$
\begin{aligned}
\mathrm{Y}=0.086+ & 0.058 \times 1+0.020 \times 2 \\
& +0.617 \times 3-0.340 \times 4 \\
& +0.739 \times 5-0.204 \times 6 \\
& +1.086 \times 7+0.050 \times 8
\end{aligned}
$$

Persamaan tersebut bermakna jika:

1. Konstanta (a) sebesar $\mathbf{0 . 0 8 6}$ menyatakan bahwa jika nilai Kinerja $\left(\mathrm{X}_{1}\right)$, Pelayanan $\left(\mathrm{X}_{2}\right)$, Fitur $\left(\mathrm{X}_{3}\right), \quad$ Reliabilitas $\left(\mathrm{X}_{4}\right)$, Conformance $\left(\mathrm{X}_{5}\right)$, Durabilitas $\left(\mathrm{X}_{6}\right), \quad$ Penampilan $\left(\mathrm{X}_{7}\right)$ dan Reputasi $\left(\mathrm{X}_{8}\right)$ adalah konstan $=0$, maka nilai konstanta untuk kepuasan konsumen adalah $\mathbf{8 . 6 \%}$

2. Kinerja (X1) bahwa setiap penambahan sebesar 1 skor maka kepuasan pelanggan akan meningkat sebesar $0.058(\mathbf{5 . 8 \%})$.

3. Pelayanan $\left(\mathbf{X}_{2}\right)$, bahwa setiap penambahan sebesar 1 skor maka kepuasan pelanggan akan meningkat sebesar $0.020(\mathbf{2 \%})$.

4. Fitur $\left(\mathbf{X}_{\mathbf{3}}\right)$, bahwa setiap penambahan sebesar 1 skor maka kepuasan pelanggan akan meningkat sebesar 0.617 (61.7\%).

5. Reliabilitas $\left(\mathbf{X}_{4}\right)$, bahwa setiap penambahan sebesar 1 skor maka kepuasan pelanggan akan menurunkan sebesar 0.340 (34\%).

6. Conformance $\left(\mathbf{X}_{5}\right)$, bahwa setiap penambahan sebesar 1 skor kepuasan pelanggan akan meningkat sebesar $0.739(\mathbf{7 3 . 9 \%})$

7. Durabilitas $\left(\mathbf{X}_{\mathbf{6}}\right)$, bahwa setiap penambahan sebesar 1 skor maka kepuasan pelanggan akan menurun sebesar 0.204 (24\%).

8. Penampilan $\left(\mathbf{X}_{7}\right)$, bahwa setiap penambahan sebesar 1 skor maka kepuasan pelanggan akan meningkat sebesar 1.086 (108.6\%).

9. Reputasi ( $\left.\mathbf{X}_{\mathbf{8}}\right)$, bahwa setiap penambahan sebesar 1 skor maka kepuasan pelanggan akan meningkat sebesar $0.050(5 \%)$.

10. Jika dari 8 indikator kualitas produk dinaikan sebesar 1 skor maka kepuasan pelanggan akan 


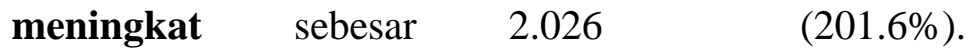

Tabel 3.3.

ANOVA $^{\mathrm{a}}$

\begin{tabular}{|ll|l|l|l|l|l|}
\hline \multicolumn{2}{|l|}{ Model } & $\begin{array}{l}\text { Sum of } \\
\text { Squares }\end{array}$ & & $\begin{array}{l}\text { Mean } \\
\text { Square }\end{array}$ & F & Sig. \\
\hline \multirow{2}{*}{1} & Regression & 280.680 & 8 & 35.085 & 89.621 & $.000^{\mathrm{b}}$ \\
& Residual & 153.070 & 391 & .391 & & \\
& Total & 433.750 & 399 & & & \\
\hline
\end{tabular}

a. Dependent Variable: Y

b. Predictors: (Constant), X8, X2, X4, X6, X3, X5, X7, X1

Dari hasil pengolahan data di atas terlihat bahwa nilai $\mathrm{F}$ sebesar 89,621 dengan tingkat signifikan angka (probabilitas Sig.) sebesar 0,000, dimana $0,000<\alpha 0,05$. Dengan demikian Ho ditolak. Maka dapat disimpulkan bahwa pengaruh kualitas produk terhadap kepuasan pelanggan pada rumah makan bebek dan yang goreng pak ndut solo adalah signifikan.

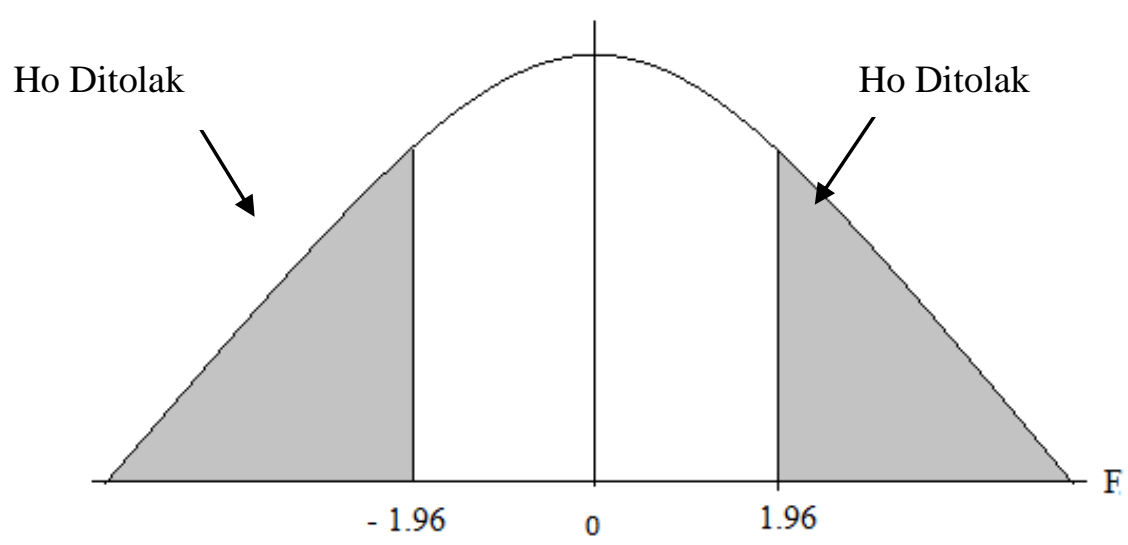

Gambar 3.1.

Kurva Distribusi F

Distribution Curve F

Sumber: diolah oleh penulis, 2015.

Berdasarkan gambar kurva di atas dapat dijelaskan bahwa nilai $\mathrm{F}$ hitung $>\mathrm{F}$ tabel yaitu 89,621> 1,96. Oleh karna itu, dapat dikatakan bahawa persamaan garis regresi linear berganda dalam penelitian ini dapat digunakan dengan baik untuk memprediksi setiap perubahan baik kenaikan ataupun penurunan. Yang berarti bahawa terdapat pengaruh yang signifikan antara kualitas produk terhadap kepuasan konsumen di rumah makan bebek dan ayam goreng Pak Ndut. 


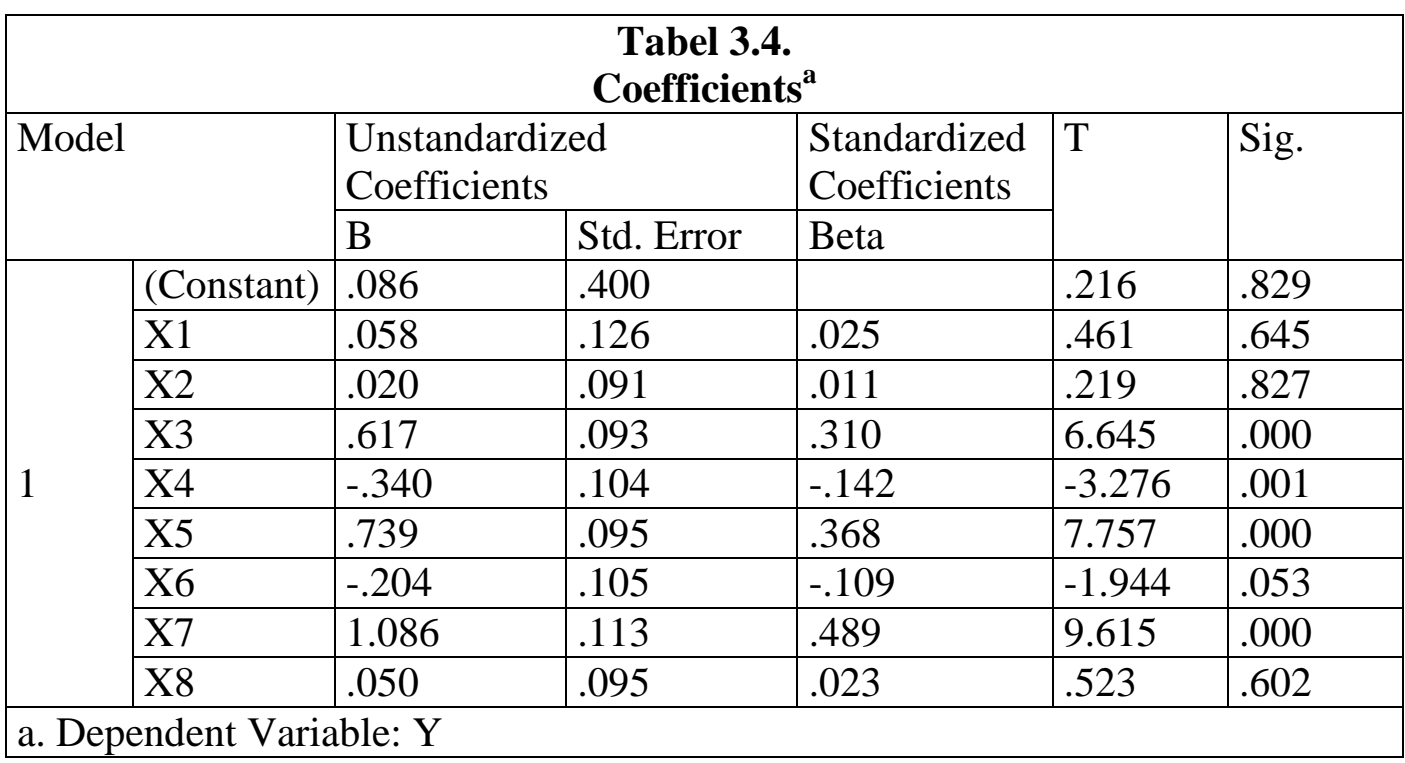

Dari hasil pengolahan data di atas terlihat bahwa nilai probabilitas (Sig) adalah sebesar $0.829 \quad$ (Sig.0,001 < $\alpha 0,05)$. Dengan demikian Ho ditolak. Maka dapat disimpulkan bahwa pengaruh kualitas produk terhadap kepuasan pelanggan pada rumah makan bebek dan ayam goreng pak ndut solo adalah signifikan.

\section{Kurva Distribusi t}

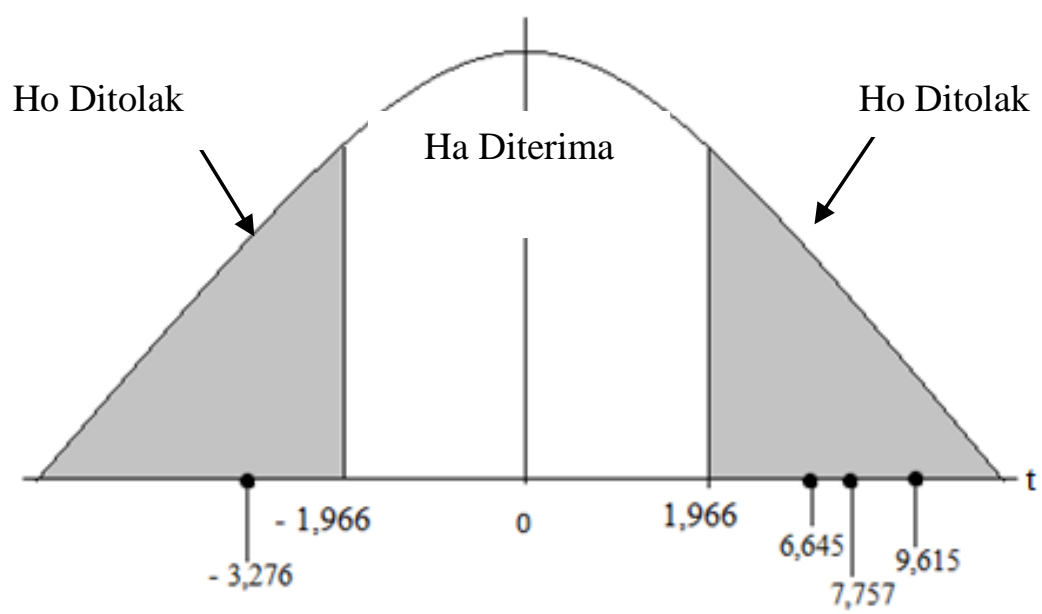

Gambar 3.2.

Kurva Distribusi t

Distribution Curve t

Sumber: diolah oleh penulis, 2015

Berdasarkan gambar kurva diatas diketahui bahwa keempat variabel bebas tersebut memiliki hubungan yang sangat signifikan terhadap kepuasan pelanggan.hal ini ditunjukkan oleh keberadaan variabel bebas tersebut dengan $\mathrm{t}$ hitung memiliki nilai yang lebih besar dari nilai t tabel yaitu 1,966 > 0,05. Hal ini juga memberikan penjelasan bahwa variabel bebas tersebut 
memiliki hubungan yang positif atau searah, artinya setiap perubahan yang terjadi karna peningkatan kualitas produk dapat menyebabkan peningkatan Kepuasan konsumen. Maka dapat disimpulkan bahwa terdapat hubungan yang signifikan antara variabel bebeas terhadap kepuasan konsumen. Dengan demikian hipotesis dapat dibuktikan.

Tabel 3.5. Model Summary ${ }^{\mathrm{b}}$

\begin{tabular}{|l|l|l|l|l|}
\hline $\begin{array}{l}\text { Mode } \\
1\end{array}$ & $\mathrm{R}$ & $\mathrm{R}$ Square & $\begin{array}{l}\text { Adjusted R } \\
\text { Square }\end{array}$ & $\begin{array}{l}\text { Std. Error of } \\
\text { the Estimate }\end{array}$ \\
\hline 1 & $.804^{\mathrm{a}}$ & .647 & .640 & .62569 \\
\hline
\end{tabular}

a. Predictors: (Constant), X8, X2, X4, X6, X3, X5, X7, X1

b. Dependent Variable: Y

Dari data tabel di atas menunjukkan bahwa nilai korelasi antara variabel independen yaitu kualitas produk dan variabel dependen yaitu kepuasan konsumen adalah sebesar 0.804 . koefisien determinasi (R2) atau $\mathrm{R}$ Square $=0.647$ atau sebesar $64.7 \%$ berarti kualitas produk berpengaruh terhadap kepuasan pelanggan pada rumah makan bebek dan ayam goreng pak ndut solo sebesar $64.7 \%$, sementara $35.3 \%$ lainnya adalah kontribusi variabel lain yang tidak termasuk di dalam model regresi ini (dipengaruhi oleh faktorfaktor lain).

\section{Kesimpulan}

1. Kualitas produk yang ditawarkan oleh rumah makan bebek dan ayam goreng Pak Ndut selama ini telah memuaskan konsumennya terbukti dengan kuesioner yang diisi oleh para konsumen sebagian besar memberikan penilaian setuju (baik). Namun di dalam 8 dimensi tersebut ada 2 dimensi yaitu fitur (0.340) dan conformance $-(0.204)$ yang menurut responden kurang baik.

2. Kepuasan konsumen rumah makan Pak Ndut berdasarkan nilai rata rata indeks tingkat kepuasan sebesar $100.1 \%$. Hal tersebut menandakan bahwa konsumen sudah merasa puas dengan kualitas produk yang disajikan oleh Rumah Makan Bebek dan Ayam Goreng Pak Ndut. Indeks tingkat kepuasan konsumen yang lebih dari 100\% yaitu terdapat dalam dimensi kinerja (100.06\%), fitur (100.06\%), conformance $(100.3 \%)$, reliabilitas $(102.28 \%)$ dan penampilan (100.93\%). Sedangkan Indeks tingkat kepuasan konsumen yang kurang dari $100 \%$ yaitu terdapat dalam dimensi Pelayanan (99.63\%), reliabilitas $(98.12 \%)$, dan reputasi (99.63).

3. Nilai korelasi antara variabel Kualitas Produk dengan variabel Kepuasan Konsumen memiliki nilai sebesar 0.710 yang artinya bahwa terdapat pengaruh antara variabel Kualitas Produk terhadap Kepuasan Konsumen. Dapat diihat pada kurva uji $f$ dan $t$ bahwa dalam uji f bahwa nilai $\mathrm{F}$ hitung $>\mathrm{F}$ tabel yaitu 89,621 >1,96. Yang berarti bahawa terdapat pengaruh yang signifikan antara kualitas produk terhadap kepuasan konsumen di rumah makan bebek dan ayam goreng Pak Ndut. Didalam uji t juga dijelaskan bahwa $t$ hitung 
memiliki nilai yang lebih besar dari nilai t tabel yaitu $1,966>0,05$. Maka dapat disimpulkan bahwa terdapat hubungan yang signifikan antara variabel bebeas terhadap kepuasan konsumen. Dengan demikian hipotesis dapat dibuktikan.

\section{Daftar Pustaka}

Albertus Ferry Rostya Adi. 2012. Analisis Pengaruh Harga, Kualitas Produk, dan Kualitas Layanan Terhadap Kepuasan Pelanggan. Makalah Program Sarjana Universitas Diponegoro, Semarang.

Buchari Alma. 2011. Manajemen Pemasaran dan Pemasaran Jasa, Alfabeta, Bandung.

Cecep Hidayat. 1998. Manajemen Pemasaran. Badan penerbit IPWI. Jakarta

Chandan

Dewantar.

2010 Mempertahankan Brand Image Bebek dan Ayam Goreng Sari Rasa Pak Ndut Sebagai Restoran Bebek Goreng Dengan Varian Menu Melalui Iklan Media Cetak. Karya Ilmiah program Diploma Tiga Akademi Kominukasi Bina Sarana Informatika, Jakarta.

Converse, Paul D, Fred M Jones. 2011. Manajemen Pemasaran dan Pemasaran Jasa. Alih Bahasa: Buchari Alama. Alfabeta, Bandung.

Converse, Paul D, Harvey W. Huege, dan Robert V. Mitchell. 2011. Manajemen Pemasaran dan Pemasaran Jasa. Alih Bahasa: Buchari Alama. Alfabeta, Bandung.

David W., Cravens. 1996. Pemasaran Strategis.Edisi 4, Erlangga, Jakarta.
Danang Sunyoto. 2012. Konsep Dasar Riset Pemasaran \& Perilaku Konsumen, CAPS, Yogyakarta.

Danang Sunyoto. 2013. Dasar - Dasar Manajemen Pemasaran, CAPS, Yogyakarta.

Indriyo Gitosudarmo. 1994, Manajemen Pemasaran. Bpfe, Yogyakarta

Kotler, Philip. 1990. Manajemen Pemasaran: Analisis, Perencanaan, dan Pengendalian, Erlangga, Jakarta.

Kotler, Philip. 2002. Manajemen Pemasaran: Analisis Perencanaan, Implementasi dan Kontrol, Erlangga, Jakarta.

Kotler, Philip dan Amstrong. 2003. Dasar - Dasar Pemasaran. Edisi 9, Indeks, Jakarta.

Kotler, Philip dan Kevin Lane Keller. 2009. Manajemen Pemasaran, Erlangga, Jakarta.

Kotler, Philip. 2011. Manajemen Pemasaran dan Pemasaran Jasa. Alih Bahasa: Buchari Alama. Alfabeta, Bandung

Mamang S, Etta dan Sopiah. 2013. Perilaku Konsumen. Penerbit Andi Yogyakarta, Yogyakarta.

Sofjan Assauri, 2013. Manajemen pemasaran, PT. RajaGrafindo Persada, Jakarta.

Stanton, William J. 1993. Prinsip Pemasaran, Erlangga, Jakarta

Sugiyono. 2011. Metode Penelitian Kuantitatif Kualitatif dan $R \& D$, Alfabeta, Bandung.

Sugiyono. 2013. Cara Mudah Menyusun Skripsi, Tesis, dan Disertasi, Alfabeta, cv, Bandung. 